University of Nebraska - Lincoln

DigitalCommons@University of Nebraska - Lincoln

Faculty Papers and Publications in Animal

Science

Animal Science Department

2004

\title{
Consumer Sensory Acceptance and Value for Beef Steaks of Similar Tenderness, but Differing in Marbling Level
}

\author{
K. M. Killinger \\ University of Nebraska-Lincoln \\ Chris R. Calkins \\ University of Nebraska-Lincoln, ccalkins1@unl.edu \\ W. J. Umberger \\ University of Nebraska-Lincoln \\ D. M. Feuz \\ University of Nebraska-Lincoln \\ Kent M. Eskridge \\ University of Nebraska-Lincoln, keskridge1@unl.edu
}

Follow this and additional works at: https://digitalcommons.unl.edu/animalscifacpub

Part of the Animal Sciences Commons

Killinger, K. M.; Calkins, Chris R.; Umberger, W. J.; Feuz, D. M.; and Eskridge, Kent M., "Consumer Sensory Acceptance and Value for Beef Steaks of Similar Tenderness, but Differing in Marbling Level" (2004). Faculty Papers and Publications in Animal Science. 583.

https://digitalcommons.unl.edu/animalscifacpub/583

This Article is brought to you for free and open access by the Animal Science Department at DigitalCommons@University of Nebraska - Lincoln. It has been accepted for inclusion in Faculty Papers and Publications in Animal Science by an authorized administrator of DigitalCommons@University of Nebraska - Lincoln. 


\title{
Consumer sensory acceptance and value for beef steaks of similar tenderness, but differing in marbling level ${ }^{1}$
}

\author{
K. M. Killinger*, C. R. Calkins ${ }^{* 2}$, W. J. Umberger $\dagger$, D. M. Feuz $\dagger$, and K. M. Eskridge \\ *Animal Science Department, $\dagger$ Department of Agriculture Economics, and $\ddagger$ Department of Biometry, \\ University of Nebraska, Lincoln 68583
}

\begin{abstract}
To determine consumer sensory acceptance and value of beef steaks differing in marbling level (high $=$ upper $2 / 3$ USDA Choice and low = USDA Select), but similar in Warner-Bratzler shear value, consumers in Chicago and San Francisco ( $n=124$ per city) evaluated two matched pairs of high- and lowmarbled strip steaks, and had the opportunity to participate in a silent, sealed-bid auction to purchase steaks from the same strip loins as the samples. Consumers who purchased steaks also evaluated the steaks when prepared in their homes. Based on overall acceptability ratings, consumers were categorized into three groups: 1) those who consistently found high marbling more acceptable, 2) those who consistently found low marbling more acceptable, and 3) those who were indifferent. Consumers who evaluated at least one high-marbled and one low-marbled sample in their home were included in an evaluation environment analysis $(\mathrm{n}=$ 50). High-marbled steaks were rated higher $(P<0.01)$ in juiciness, flavor, and overall acceptability than low-
\end{abstract}

marbled steaks. In Chicago, consumers tended to bid more $(P<0.10)$ for high-marbled steaks, whereas consumers in San Francisco did not. Consumers who found high-marbled steaks more acceptable and those who found low-marbled steaks more acceptable were willing to pay more $(P<0.01)$ for the more acceptable product. Consumers who evaluated high- and low-marbled samples in both the laboratory and home environments rated high- and low-marbled samples similar $(P>0.10)$ in flavor, juiciness, tenderness and overall acceptability when evaluating the steaks in their homes. In addition, these consumers were willing to pay similar $(P>0.10)$ amounts for high- and low-marbled samples in both environments. Overall, consumers found high-marbled steaks to be more acceptable than low-marbled steaks in flavor and overall acceptability when tenderness differences were minimized in the laboratory environment. Consumers were willing to pay more for their preference, whether that preference was for high-marbled or low-marbled steaks.

Key Words: Beef Quality, Consumer Panels, Consumer Prices

(C2004 American Society of Animal Science. All rights reserved.

J. Anim. Sci. 2004. 82:3294-3301

\section{Introduction}

The Beef Industry Long Range Plan targeted beef quality and consistency as an area that affects the success of the beef industry (NCBA, 1996). Therefore, emphasis was placed on decreasing consumer dissatisfaction with eating quality, especially with regard to tenderness. Consumers have indicated that beef tenderness is an important attribute (Huffman et al., 1996), and that they are willing to pay more for beef products that are known to be tender (Boleman et al., 1997; Miller et al., 1998). Although George et al. (1999)

\footnotetext{
${ }^{1}$ Published as Paper No. 11401, Journal Series, Nebraska Agric. Res. Div., Univ. of Nebraska, Lincoln 68583-0908.

${ }^{2}$ Correspondence: A213 Animal Science (phone: 402-472-6314; fax: 402-472-6362; e-mail: ccalkins1@unl.edu).

Received February 28, 2003.

Accepted July 21, 2004.
}

indicated that there is still room for improvement in retail beef tenderness, the question remains: Will an improvement in tenderness alone increase consumer satisfaction with the eating quality of beef? Also, as improvements are made in the consistency of beef tenderness, will other palatability attributes become more important?

Flavor and juiciness are attributes that also contribute to the eating quality of beef. Many factors can influence these attributes, but marbling level is currently used as a visual indicator of palatability in the beef quality grading system (USDA, 1997). Studies have shown that increased marbling levels increase consumer acceptance of fresh beef steaks (Savell et al., 1987; Neely et al., 1998); however, few studies have compared differences in consumer acceptance of beef differing in marbling level when tenderness differences were minimized. Therefore, the objective of this study was to examine consumer sensory acceptance and value 
of beef strip steaks differing in marbling level but similar in tenderness.

\section{Materials and Methods}

Taste panel testing was conducted in the Chicago and San Francisco areas. This study was conducted as a portion of a study involving visual evaluation of beef, as well as sensory evaluation of several beef samples.

\section{Collection of Strip Loins}

Two hundred ninety-three beef strip loins (NAMP, 1997) of three quality levels (Moderate/Modest, Small, and Slight degrees of marbling) were purchased from a commercial meat processor and delivered to the Loeffel Meat Laboratory at the University of Nebraska-Lincoln. Strip loins were aged for $7 \mathrm{~d}$ at $3^{\circ} \mathrm{C}(9 \mathrm{~d}$ total aging time), and subsequently frozen at $-35.5^{\circ} \mathrm{C}$ until further fabrication. Strip loins were tempered in a $3^{\circ} \mathrm{C}$ cooler for a period of no more than $24 \mathrm{~h}$ before being cut into 2.54-cm-thick steaks on a band saw (Biro Manufacturing Co., Marblehead, OH). Steaks were trimmed to approximately $0.3 \mathrm{~cm}$ external fat, individually wrapped in butcher paper, labeled, and returned to the freezer.

\section{Warner-Bratzler Shear Force Determination}

The most anterior steak (Steak 1) was collected from each strip loin and thawed at $4^{\circ} \mathrm{C}$ for approximately 24 h. Marbling scores were either assigned previously by a USDA grader or by two trained individuals (scores were averaged), depending on when the loins were purchased. Steaks were cooked on Open Hearth Broilers (Farberware, Bronx, NY), and internal temperature was monitored intermittently with a thermocouple thermometer (model 450-ATT; Omega Engineering, Inc., Stamford, CT). Steaks were turned at $35^{\circ} \mathrm{C}$ and cooked to a final end point temperature of $70^{\circ} \mathrm{C}$. Steaks were cooled for approximately $2 \mathrm{~h}$ at $18^{\circ} \mathrm{C}$. Then, eight or more $1.27-\mathrm{cm}$-diameter cores were removed from the steaks parallel to the longitudinal orientation of the muscle fibers using a mechanical coring device (model 11-950; Delta, Pittsburgh, PA). Cores were sheared perpendicular to the longitudinal orientation of muscle fibers with a Warner-Bratzler shear head attached to an Instron Universal Testing Machine (model 55R1123; Instron Corp., Canton, MA) equipped with a 500-kg load cell and a crosshead setting of $250 \mathrm{~mm} / \mathrm{min}$. Peak shear force data were collected and recorded using accompanying Merlin software (Instron Corp.).

\section{Chemical Analyses}

The second-most anterior steak (Steak 2) was reserved for proximate analysis. Steaks were thawed, trimmed of external fat, and cut into small pieces. Then, samples were pulverized in liquid $\mathrm{N}$ using a Waring blender (Dynamics Corp. of America, New Hartford,
CT). Duplicate samples were analyzed for moisture and ash using a thermogravimetric analyzer (Leco Corp., St. Joseph, MI). For lipid content, duplicate samples were analyzed using the Soxhlet method (AOAC, 1990) and distilled in anhydrous ether for $72 \mathrm{~h}$.

\section{Pairing of Strip Loins}

Strip loins with Modest/Moderate marbling were considered "high marbled" and strip loins with Slight marbling were considered "low marbled." High-marbled (upper $2 / 3$ USDA Choice) strip loins were paired with low-marbled (USDA Select) strip loins based on similar $(<0.15 \mathrm{~kg})$ Warner-Bratzler shear force values. For sensory evaluation, warm-up samples were included as recommended by the AMSA (1978) guidelines. Because marbling level was being studied, it was decided that the warm-up samples should be of an intermediate level; thus, warm-up samples were selected from strip loins with a Small degree of marbling, and randomly assigned to evaluation sessions.

For each city, 24 matched pairs of strip loins were randomly assigned to evaluation sessions, with each session having two matched pairs differing in marbling. Steaks 3 through 5 (anterior to posterior) were designated for taste panel samples, whereas steaks 6 through 11 were designated for sale during experimental auctions. Frozen steaks used in the auctions were packaged as pairs to achieve packages that weighed about $0.45 \mathrm{~kg}$ total when thawed. Steaks were shipped frozen to the host facilities and held in freezers at the facilities $\left(-26^{\circ}\right.$ and $-12.2^{\circ} \mathrm{C}$ in Chicago and San Francisco, respectively) for less than $1 \mathrm{wk}$ before the evaluation sessions.

\section{Screening of Panelists}

Consumers in both cities were screened over the telephone by employees of the host facilities to determine whether they qualified for the study. To qualify, consumers had to be the primary grocery shopper in the household or share shopping duties equally with another member of the household. In addition, consumers had to be between the ages of 19 to 59 and had to be willing to consume beef. Consumers, and their immediate families, could not be employed in any portion of the meat animal industry, market research, advertising, or news reporting. In each city, qualified consumers were scheduled for evaluation sessions that were held for 3 $\mathrm{d}$ with four sessions per day, targeting 12 consumers/ session.

In each city, 124 consumers participated in the study. Participation in each evaluation session ranged from six to 12 consumers. The majority of consumers (>90\%) were $35 \mathrm{yr}$ of age or older, and most (95\%) consumed beef in their homes three to four or more, times each week. In Chicago, $82.3 \%$ of consumers were female, and 97.5\% were Caucasian, whereas in San Francisco 77.4\% were female, and $81.9 \%$ were Caucasian. 


\section{Collection of Demographic Information}

Consumers who qualified and agreed to participate were mailed a consent form and a survey that ascertained information on their eating preferences, meat purchasing behaviors, and other demographic characteristics. On arrival at the facility, consumers were paid in cash with amounts comparable to other test marketing facilities in the respective cities $(\$ 25$ in Chicago and $\$ 35$ in San Francisco). Panelist identification codes were assigned to maintain anonymity throughout the procedures, and all consumers completed a meat knowledge survey.

\section{Taste Panel Sample Preparation}

While the consumers were arriving, taste panel samples were cooked in the test kitchen of the facility. Steaks 3, 4, and 5 were prepared for sensory evaluation. Frozen steaks were thawed in a walk-in cooler or refrigerator $\left(1^{\circ} \mathrm{C}\right)$ for approximately $24 \mathrm{~h}$, and cooked on Open-Hearth broilers in accordance with AMSA (1978) guidelines to an internal temperature of $70^{\circ} \mathrm{C}$. Whole steaks were then wrapped in aluminum foil with an identification tag, and held in a steam-jacketed table (Hot Food Boxes, Inc., Chicago, IL) or waterless food warmer (Duke Manufacturing, St. Louis, MO) until immediately before serving. Steaks were then cut into 1$\times 2-\times 1$-cm pieces, and a single piece was placed on a plate and served to each consumer.

\section{Explanation of Auction Procedures}

To maintain consistency throughout the evaluation sessions, a moderator read a written explanation of the experimental auction procedures to the consumers. The written explanation by Menkhaus et al. (1990) was used as a model when developing the explanation used in this study. In brief, the explanation informed the consumers that they would have the opportunity to purchase steaks from the same strip loins as the taste panel samples by submitting bids in a silent, sealed-bid auction; however, they were not required to participate in the auctions. In each auction, three packages of steaks would be sold. Winners of the auction would be the three consumers submitting the three highest bids; however, in a Vickery (uniform-price) auction, all three winners do not pay the amount of their individual bids; instead, all three pay the same price for the steaks. The price all three winners paid, called the "market price," was the amount of the fourth-highest bid. Because winners generally did not pay the amount that they bid, it was in the best interest of the consumer to bid the amount that they were truly willing to pay for the product (Vickery, 1961). As outlined by Vickery (1961), consumers who bid more than their value for the product increase their chances of winning but at an unprofitable price. Consumers who bid less than their value for the product decrease the likelihood of winning at what would be a profitable price because consumers generally pay less than the amount of their bid. This rationale was explained to the consumers, and specific examples were used to reinforce this idea. Procedures in the case of a tie were also explained. Record-keeping procedures were described in detail after each consumer received a folder containing two auction bid sheets and a panelist record sheet. Because consumers were not required to bid, consumers who submitted a bid of $\$ 0.00$ (nonparticipation) were asked to provide an explanation for their decision on the auction bid sheet.

\section{Practice Auctions}

After the explanation, three practice auctions were conducted. Because steaks from the visual evaluation (Killinger et al., 2004) were visible during the practice auctions, it was decided that those steaks should be used as the products for the first two practice auctions. For the first practice auction, the consumers were told that they would be bidding on a $0.45-\mathrm{kg}$ package of steak similar to one of the visual evaluation steaks. Completed auction bid sheets were collected, and the bids were written on a white board in ascending order. The moderator pointed out winning bids and the market price. The moderator also recorded the market price and winning bids on a practice auction results form, whereas the consumers recorded the results on their record sheets. A second practice auction was conducted in the same manner using another steak from the visual evaluation. These practice auctions were important because they familiarized consumers with an auction procedure that was probably unfamiliar to them. In Vickery auctions, bids tend to converge to a stable price over several bidding sequences (Coppinger et al., 1980); therefore, the practice auctions provided more opportunity for bids to stabilize before beginning the binding, purchase auctions. Also, Coppinger et al. (1980) noted that numerous bidding sequences were necessary for participants to learn that the most successful strategy in a Vickery auction was to bid amounts equal to their value for the product.

Once all questions and concerns were addressed, consumers were told the third practice auction would be conducted in the taste panel booths, and they would evaluate a steak sample and then bid for a $0.45-\mathrm{kg}$ package of frozen steak from the same strip loin as the taste panel sample. Consumers were reminded that the warm-up evaluation and auction were simply to practice the auction procedures. Consumers were seated at the booth labeled with their panelist identification number. Panelists were then given an evaluation form and a steak sample (warm-up sample), and consumers evaluated the sample, completed the evaluation form, and returned the form to the servers. Then, the panelists were given an auction bid sheet, which was completed and returned to the servers. Winning bids and market price were determined in the test kitchen by the serving personnel, and the market price was announced by the moderator. Consumers were reminded 
that if their submitted bid was above the market price, they had won the auction, whereas if their bid was at or below the market price, they had not won the auction. This final practice auction allowed consumers to become familiar with the taste panel evaluation forms, and by tasting a warm-up sample, the bias associated with order of sampling was minimized.

\section{Taste Panel Evaluations and Purchase Auctions}

Consumers were reminded that the rest of the auctions would be binding, and a winning bid would require the consumer to pay the market price determined in that auction. They were reminded that they would be bidding for a $0.45-\mathrm{kg}$ package of frozen steaks (two steaks per package) from the same strip loin as the taste panel samples. Consumers rated samples for juiciness, tenderness, flavor, and overall acceptability using eight-point scales ( 1 = extremely dry, tough, and undesirable to $8=$ extremely juicy, tender, and desirable). Consumers separately evaluated each high- and lowmarbled sample in a matched pair, and after evaluating both samples, consumers were given two auction bid sheets (one for each sample they had tasted). Consumers submitted their bids and recorded them on their record sheets. Servers collected the bid sheets and determined the winning bids and the market prices. After evaluating two samples and conducting two auctions, the process was repeated. Servers kept records of winning bids, as well as the market prices.

\section{Reconciliation of Accounts and Steak Distribution}

After completing the last auction, consumers, the moderator, and servers gathered in the conference room. If consumers had not purchased any steaks and their records agreed with the servers' records, they were free to leave. Then a server reconciled their records with each consumer's records, and consumers bought the steaks that they had won. Consumers who purchased steaks were given a follow-up evaluation form and an addressed, stamped envelope for each set of steaks. The follow-up form asked consumers to provide information on steak preparation, palatability attribute rating as performed in the laboratory, and the price consumers were willing to pay for the steaks. The follow-up form also provided the market price that the consumers paid for the package of steaks.

\section{Statistical Analyses}

Differences in Warner-Bratzler shear force, marbling score, and chemical analysis data between paired highand low-marbled strip loins were analyzed using the paired $t$-test statement in the means procedure of SAS (SAS Inst., Inc., Cary, NC). Absolute means and absolute differences were reported for this data.

All 248 consumers were included in the sensory evaluation portion of the analysis. Consumers who consistently submitted bids of $\$ 0.00$ were removed from the analysis of auction bids because these consumers were unwilling to provide information on their value for the products. The most common reason given by the 22 individuals who choose never to bid was lack of a desire to purchase beef. Therefore, 226 consumers were included in the analysis of auction bids. For the taste panel and overall auction bid data, the experimental design was a split-plot with auction (Auction 1 or 2) as the whole plot and marbling level (high and low) as the split-plot factor. In the ANOVA, main effects were city (C), evaluation session (S), panelist $(\mathbf{P})$, auction $(\mathbf{A})$, and marbling level (M), and the statistical model contained the following sources of variation: $\mathrm{C}, \mathrm{S}$ nested within $\mathrm{C}, \mathrm{P}$ nested within $\mathrm{S} \times \mathrm{C}, \mathrm{A}, \mathrm{A} \times \mathrm{C}, \mathrm{A} \times \mathrm{S}$ nested within $\mathrm{C}, \mathrm{A} \times \mathrm{P}$ nested with $\mathrm{S} \times \mathrm{C}($ Error A), M nested within $\mathrm{C}, \mathrm{M} \times \mathrm{S}$ nested within $\mathrm{C}, \mathrm{M} \times \mathrm{P}$ nested within $\mathrm{S} \times \mathrm{C}$ (Error $\mathrm{B}), \mathrm{M} \times \mathrm{A}$ nested within $\mathrm{C}, \mathrm{M} \times \mathrm{A}$ $\times \mathrm{S}$ nested within $\mathrm{C}$, and $\mathrm{M} \times \mathrm{A} \times \mathrm{P}$ nested within $\mathrm{S} \times$ C. All factors were considered as fixed effects, except panelist and evaluation session, which were considered as random effects. Because consumers were not equal monetary compensation in both cities, price data between cities were not compared.

To study the auction bids of consumers who consistently found one marbling level more acceptable than the other based on overall acceptability ratings, consumers were categorized into three groups: 1) those who consistently rated high-marbled steaks higher in overall acceptability, 2) those who consistently rated low-marbled steaks higher in overall acceptability, and 3 ) those who were inconsistent. Using these acceptability groups, auction bid data were analyzed as a splitplot with acceptability group as the whole plot and marbling level as the split-plot factor. Factors included in the ANOVA were $\mathrm{C}, \mathrm{S}, \mathrm{P}$, acceptability group $(\mathbf{G}), \mathrm{A}$, and $\mathrm{M}$, as well as $\mathrm{M} \times \mathrm{C}, \mathrm{M} \times \mathrm{C} \times \mathrm{G}, \mathrm{P}$ within $\mathrm{G} \times \mathrm{S} \times$ $\mathrm{C}$ (error $\mathrm{A}$ ), $\mathrm{G}$ within $\mathrm{C}, \mathrm{G} \times \mathrm{S}$ within $\mathrm{C}, \mathrm{M} \times \mathrm{S}$ within $\mathrm{C}$, and $\mathrm{M} \times \mathrm{G} \times \mathrm{S}$ within $\mathrm{C}$.

Consumers $(n=50)$ who evaluated at least one highmarbled and one low-marbled sample in their home were included in an evaluation of the effect of environment (laboratory or home). It should be noted that these steaks were not necessarily matched for tenderness. Taste panel and price data were analyzed as a splitplot design with the whole-plot factor being evaluation environment and marbling level (high and low) as the split-plot factor. Sources of variation in the ANOVA included C, S, P, evaluation environment $(\mathbf{E}), \mathrm{M}, \mathrm{S}$ within $\mathrm{C}, \mathrm{P}$ within $\mathrm{S} \times \mathrm{C}, \mathrm{E}, \mathrm{E} \times \mathrm{C}, \mathrm{E} \times \mathrm{S}$ within $\mathrm{C}$ (error B), $\mathrm{E} \times \mathrm{P}$ within $\mathrm{S} \times \mathrm{C}$ (error $\mathrm{A}), \mathrm{M}, \mathrm{M} \times \mathrm{C}, \mathrm{M} \times$ $\mathrm{S}$ within $\mathrm{C}, \mathrm{M} \times \mathrm{E}, \mathrm{M} \times \mathrm{E} \times \mathrm{C}$, and $\mathrm{M} \times \mathrm{E} \times \mathrm{S}$ within $\mathrm{C}$.

The mixed model procedure of SAS was used for all data analyses, and means were separated using Fisher's LSD. All means reported are least squares means, except for chemical analysis, Warner-Bratzler shear force, and marbling data as mentioned previously. To evaluate association among palatability variables and auction bids after removing marbling effects, partial correlations were determined using the GLM procedure 
Table 1. Palatability ratings for high- and low-marbled strip steak samples

\begin{tabular}{lccc}
\hline \hline Attribute $^{\mathrm{a}}$ & High-marbled & Low-marbled & SE \\
\hline Flavor & $5.6^{\mathrm{b}}$ & $5.3^{\mathrm{c}}$ & 0.08 \\
Juiciness & $5.0^{\mathrm{b}}$ & $4.5^{\mathrm{c}}$ & 0.11 \\
Tenderness & $5.4^{\mathrm{b}}$ & $5.3^{\mathrm{b}}$ & 0.10 \\
Overall acceptability & $5.4^{\mathrm{b}}$ & $5.1^{\mathrm{c}}$ & 0.09 \\
\hline
\end{tabular}

asamples were rated for flavor, juiciness, tenderness, and overall acceptability using an eight-point scale $(1=$ extremely undesirable, dry, tough, and undesirable to $8=$ extremely desirable, juicy, tender, and desirable).

${ }^{\mathrm{b},{ }^{c} \text { Within a row, means without a common superscript } \operatorname{differ}, P<}$ 0.01 .

of SAS. Categorical responses on surveys were analyzed for differences between cities and between acceptability groups using the $\chi^{2}$ test.

\section{Results}

Marbling scores between paired high- and low-marbled strip loins were different $(P<0.01)$, with almost two full marbling scores difference between paired samples. Proximate analysis results confirmed that paired high- and low-marbled steaks differed $(P<0.01)$ in intramuscular fat content. Paired steaks differed in fat content by $2.76 \pm 0.50 \%$ fat, with high-marbled steaks averaging $8.81 \%$ fat and low-marbled steaks averaging $6.05 \%$ fat. High-marbled steaks also had lower $(P<$ 0.01 ) moisture and ash contents.

High- and low-marbled strip loins were paired based on similar $(P=0.72)$ Warner-Bratzler shear force values, with an average difference in Warner-Bratzler shear values of $0.001 \pm 0.004 \mathrm{~kg}$. Consumers rated highand low-marbled samples similarly $(P=0.22)$ for tenderness (Table 1). Additionally, consumers rated highmarbled steaks higher $(P<0.01)$ in flavor, juiciness, and overall acceptability than low-marbled steaks. Partial correlation coefficients were determined for palatability attribute ratings with overall acceptability ratings (Table 2). Flavor was most highly correlated $(P<0.01)$ with overall acceptability ratings, followed by tenderness, and juiciness.

Consumers in both cities found high-marbled steaks to be more $(P<0.01)$ desirable in flavor and overall acceptability; however, only consumers in Chicago were willing to pay more $(P<0.10)$ for the high-marbled
Table 3. The price $(\$ / 0.45 \mathrm{~kg})$ consumers were willing to pay for high- and low-marbled strip steaks based on auction bids

\begin{tabular}{lccc}
\hline \hline Marbling level & Chicago & San Francisco & SE \\
\hline High-marbled & $2.39^{\mathrm{a}}$ & $2.73^{\mathrm{a}}$ & 0.16 \\
Low-marbled & $2.15^{\mathrm{b}}$ & $2.68^{\mathrm{a}}$ & 0.16 \\
Price differential & 0.24 & 0.05 & 0.14 \\
\hline
\end{tabular}

${ }^{\mathrm{a}, \mathrm{b}}$ Within a column, means without a common superscript differ, $P<0.10$.

steaks (Table 3). Obviously, the bids submitted typically did not reflect retail value for fresh beef steaks. The tendency for consumers to underbid in a secondprice auction was observed by Coursey and Smith (1984); however, the amount by which consumers underbid was consistent. Thus, the bids were rank-order revealing. Menkhaus et al. (1992) suggested that when comparing two products, the differential between the bids submitted for the products represents a true difference in value (more so than the absolute bids themselves). Therefore, in this study, results from the auction data focus on the price differential between bids. Consumers in Chicago were willing to pay $\$ 0.24 / 0.45$ $\mathrm{kg}$ more for high-marbled steaks, and consumers in San Francisco were only willing to pay $\$ 0.05 / 0.45 \mathrm{~kg}$ more $(P=0.74)$ for high-marbled steaks. Partial correlations of auction bids and palatability ratings were determined (Table 2 ), and bids were highly $(P<0.01)$ correlated with overall acceptability ratings; however, partial correlation coefficients for the other palatability attributes were of similar magnitude.

Using consumer groupings based on overall acceptability, an analysis of the auction bids was performed (Table 4). In Chicago, $25.6 \%$ of consumers consistently liked high-marbled samples, $7.7 \%$ of consumers consistently liked low-marbled samples, and $66.7 \%$ of consumers were indifferent. Those who liked high marbling were willing to pay $\$ 1.13 / 0.45 \mathrm{~kg}$ more $(P<0.01)$ for the steak they found more acceptable, and those who liked low marbling were willing to pay $\$ 1.40 / 0.45$ $\mathrm{kg}$ more $(P<0.01)$ for the steak they found more acceptable. Consumers who were indifferent, based on overall acceptability scores, were willing to pay similar $(P=$ $0.45)$ amounts for high- and low-marbled steaks.

In San Francisco, 21.1\% of consumers consistently liked high-marbled samples, $11.9 \%$ of consumers liked

Table 2. Partial correlation coefficients among palatability ratings in the laboratory and auction bids

\begin{tabular}{lcccc}
\hline \hline Trait & Flavor & Juiciness & Tenderness & $\begin{array}{c}\text { Overall } \\
\text { acceptability }\end{array}$ \\
\hline Overall & & & & - \\
acceptability & $0.83^{*}$ & $0.76^{*}$ & $0.78^{*}$ & $0.57^{*}$ \\
Auction bids & $0.49^{*}$ & $0.47^{*}$ & $0.46^{*}$ &
\end{tabular}


Table 4. The price $(\$ / 0.45 \mathrm{~kg})$ consumers were willing to pay $( \pm \mathrm{SE})$, based on auction bids, for high- and low-marbled strip steaks when consumers were grouped based on consistent overall acceptability ratings in Chicago and San Francisco

\begin{tabular}{|c|c|c|c|c|c|c|}
\hline \multirow[b]{2}{*}{$\begin{array}{l}\text { Marbling } \\
\text { level }\end{array}$} & \multicolumn{3}{|c|}{ Chicago } & \multicolumn{3}{|c|}{ San Francisco } \\
\hline & $\begin{array}{l}\text { Liked high } \\
\text { marbling } \\
(\mathrm{n}=30)\end{array}$ & $\begin{array}{l}\text { Liked low } \\
\text { marbling } \\
(\mathrm{n}=9)\end{array}$ & $\begin{array}{c}\text { Indifferent } \\
(\mathrm{n}=78)\end{array}$ & $\begin{array}{l}\text { Liked high } \\
\text { marbling } \\
(\mathrm{n}=23)\end{array}$ & $\begin{array}{l}\text { Liked low } \\
\text { marbling } \\
(\mathrm{n}=13)\end{array}$ & $\begin{array}{l}\text { Indifferent } \\
(\mathrm{n}=73)\end{array}$ \\
\hline High-marbled & $3.15 \pm 0.24^{\mathrm{a}}$ & $1.02 \pm 0.40^{\mathrm{a}}$ & $2.26 \pm 0.17^{\mathrm{a}}$ & $3.64 \pm 0.26^{\mathrm{a}}$ & $0.90 \pm 0.34^{\mathrm{a}}$ & $2.75 \pm 0.17^{\circ}$ \\
\hline Low-marbled & $2.02 \pm 0.24^{b}$ & $2.42 \pm 0.40^{\mathrm{b}}$ & $2.17 \pm 0.17^{\mathrm{a}}$ & $2.17 \pm 0.26^{\mathrm{b}}$ & $2.84 \pm 0.34^{b}$ & $2.82 \pm 0.17^{\circ}$ \\
\hline Differential & $1.13 \pm 0.20$ & $1.40 \pm 0.36$ & $0.09 \pm 0.13$ & $1.47 \pm 0.22$ & $1.94 \pm 0.30$ & $0.07 \pm 0.13$ \\
\hline
\end{tabular}

${ }^{\mathrm{a}, \mathrm{b}}$ Within a column, means without a common superscript differ, $P<0.01$.

low marbling, and $67.0 \%$ of consumers were indifferent. Consumers who consistently liked high marbling were willing to pay $\$ 1.47 / 0.45 \mathrm{~kg}$ more $(P<0.01)$ for the type of steak they found more acceptable, whereas those who consistently liked low marbling were willing to pay $\$ 1.94 / 0.45 \mathrm{~kg}$ more $(P<0.01)$ for the steak they found more acceptable. Consumers who were indifferent were willing to pay similar $(P=0.59)$ amounts for high- and low-marbled steaks. In both cities, consumers with consistent overall acceptability ratings were willing to pay more for a product they thought was more acceptable.

Consumers in different acceptability groups differed in some of their eating preferences. Consumers who were indifferent (65.3\%) and $69.8 \%$ who found highmarbled beef more acceptable most often prepared beef in their homes, whereas $52.4 \%$ of those who found low marbling more acceptable prepared beef most often in their homes. Therefore, consumers who found low-marbled beef more acceptable most often prepared other meat products in their homes, such as chicken, fish, and pork. Moreover, a higher percentage $(P<0.01)$ of consumers who were indifferent $(67.3 \%)$ and who found high marbling more acceptable (73.6\%) preferred to order beef at restaurants, compared with $59.1 \%$ of consumers who found low marbling more acceptable. Hence, $47.6 \%$ of consumers who found low marbling more acceptable preferred to order other meats (such as chicken, fish or pork) at restaurants.

Of the consumers $(n=50)$ who purchased at least one high-marbled and one low-marbled steak, most (90.7\%) kept the steaks frozen for a period of time before inhome preparation. The most common preparation method was grilling (68.5\%), followed by broiling (15.4\%), and the highest percentage of consumers prepared their steaks to medium-well (35.9\%), followed by medium-rare $(22.9 \%)$, medium $(20.6 \%)$, and welldone (16.0\%).

There was a significant $(P<0.01)$ main effect for evaluation environment for flavor, juiciness, and overall acceptability. Consumers' ratings, averaged over high- and low-marbled steaks, were higher when evaluating the steaks in their homes. More importantly, however, were the data provided by consumer evaluation of high- and low-marbled steaks when evaluated in the laboratory and home environments (Table 5). These 50 consumers differed slightly in their laboratory evaluations when compared with the overall results for all participants in the laboratory sensory evaluation. As reported previously, when the 248 consumers were considered together, high-marbled steaks were rated higher in flavor, juiciness, and overall acceptability, whereas tenderness ratings were similar for high- and low-marbled steaks. In the laboratory environment, the 50 consumers included in the analysis of evaluation environment rated high-marbled steaks higher in flavor, tenderness, and overall acceptability $(P<0.05)$; however, they rated high- and low-marbled samples similarly for juiciness $(P>0.10)$. It is interesting that this subsample of 50 consumers evaluated high- and low-marbled samples somewhat differently than the 248 consumers as a whole. More importantly, the consumers' evaluations in the laboratory environment helped to anchor the findings of the in-home portion of the study. In their homes, consumers rated high- and low-marbled samples similarly for flavor $(P=0.95)$, juiciness $(P=0.86)$, tenderness $(P=0.90)$, and overall acceptability $(P=0.57)$. The attribute that correlated most highly with overall acceptability was tenderness $(\mathrm{r}=0.87 ; P<0.001)$, followed by flavor $(\mathrm{r}=0.76 ; P<$ $0.001)$, and juiciness $(\mathrm{r}=0.65 ; P<0.001)$.

When prices for high- and low-marbled steaks were averaged together, consumers were willing to pay more $(P<0.01)$ for steaks evaluated in the home compared with bids in the laboratory. However, marbling level had a greater influence on the amount consumers were willing to pay for steaks than the environment in which the steaks were evaluated. Moreover, this subsample of consumers was willing to pay similar $(P=0.47)$ amounts for high- and low-marbled steaks in the laboratory environment, only $\$ 0.15 / 0.45 \mathrm{~kg}$ more for highmarbled steaks (Table 6). This carried through to the home environment as well, where consumers were willing to pay only $\$ 0.13 / 0.45 \mathrm{~kg}$ more $(P=0.54)$ for highmarbled steaks when evaluated in the home. Overall satisfaction seemed to be high with all steaks evaluated in the home, with $90.8 \%$ of consumers willing to purchase the product again. 
Table 5. Palatability ratings by consumers who evaluated high and low marbled steaks in both the laboratory and home environments

\begin{tabular}{lcccccc}
\hline \hline & \multicolumn{2}{c}{ Laboratory } & & \multicolumn{3}{c}{ Home } \\
\cline { 2 - 3 } \cline { 5 - 6 } Attribute $^{\mathrm{a}}$ & $\begin{array}{c}\text { High } \\
\text { marbled }\end{array}$ & $\begin{array}{c}\text { Low } \\
\text { marbled }\end{array}$ & & $\begin{array}{c}\text { High } \\
\text { marbled }\end{array}$ & $\begin{array}{c}\text { Low } \\
\text { marbled }\end{array}$ & SE \\
\hline Flavor & $6.2^{\mathrm{b}}$ & $5.9^{\mathrm{c}}$ & & $6.7^{\mathrm{b}}$ & $6.7^{\mathrm{b}}$ & 0.14 \\
Juiciness & $5.5^{\mathrm{b}}$ & $5.2^{\mathrm{b}}$ & & $6.2^{\mathrm{b}}$ & $6.2^{\mathrm{b}}$ & 0.19 \\
Tenderness & $6.1^{\mathrm{b}}$ & $5.6^{\mathrm{c}}$ & & $6.2^{\mathrm{b}}$ & $6.2^{\mathrm{b}}$ & 0.18 \\
Overall acceptability & $6.2^{\mathrm{b}}$ & $5.7^{\mathrm{c}}$ & & $6.5^{\mathrm{b}}$ & $6.4^{\mathrm{b}}$ & 0.16 \\
\hline
\end{tabular}

${ }^{a}$ Samples were rated for flavor, juiciness, tenderness, and overall acceptability using an eight-point hedonic scale $(1=$ extremely undesirable, dry, tough, and undesirable to $8=$ extremely desirable, juicy, tender and desirable).

${ }_{\mathrm{b}, \mathrm{c}}$ In each environment within a row, means lacking a common superscript differ, $P<0.05$.

\section{Discussion}

At similar tenderness levels, consumers found highmarbled steaks to be juicier, as well as more desirable in flavor and overall acceptability. Other studies involving consumer evaluation of high- and low-marbled steaks have found that high-marbled steaks were more acceptable (Savell et al., 1987, 1989; Neely et al., 1998). In this study, high- and low-marbled samples were matched based on similar Warner-Bratzler shear force values, indicating the importance of marbling level and its effects on palatability when tenderness differences were minimized.

Some demographic characteristics in the current study were linked with acceptability groups (Umberger, 2001). As consumer age increased, consumers were more likely to consistently find the high-marbled steak more acceptable, and less likely to find the low-marbled steak more acceptable. Consumers with higher education levels were more likely to be indifferent. Additionally, if consumers typically did not purchase U.S. Choice beef, then they were more likely to consistently like low marbling. It seems that if consumers were not familiar with the taste of U.S. Choice beef, then they were more likely to consistently find low marbling more acceptable.

In published studies (Savell et al., 1987, 1989; Neely et al., 1998), consumers found high-marbled steaks to be more acceptable when evaluated in their homes. It is interesting that the consumers who participated in the in-home evaluation in this study did not find differences between high- and low-marbled steaks; however,

Table 6. The price $(\$ / 0.45 \mathrm{~kg})$ consumers were willing to pay ( \pm SE) for high and low marbled steaks when evaluated in both the laboratory and home environments

\begin{tabular}{lccc}
\hline \hline Marbling level & $\begin{array}{c}\text { Bid at } \\
\text { laboratory }\end{array}$ & $\begin{array}{c}\text { Price } \\
\text { at home }\end{array}$ & SE \\
\hline High marbled & 3.90 & 4.95 & \pm 0.23 \\
Low marbled & 3.75 & 4.82 & \pm 0.23 \\
Differential & 0.15 & 0.13 & \pm 0.21 \\
\hline
\end{tabular}

this portion of the study was conducted with a smaller number of consumers, and no efforts were made to have consumers evaluate steaks on a consistent basis. Furthermore, the steaks were not necessarily matched for tenderness. Consumers in this study indicated that they regularly apply a variety of condiment/flavoring products to steaks when prepared in the home, and this was consistent with their preparation of the steaks from this study in their homes. However, $63.6 \%$ of consumers in Chicago and $51.6 \%$ of consumers in San Francisco indicated that they would not apply these condiment/ flavoring products if steaks were more flavorful by themselves. Thus, the flavor of steaks is important to consumers, and some consumers are interested in identifying steaks that do not need additional flavor products.

Although most consumers (51\%) in the survey identified tenderness as the attribute that contributes most to eating satisfaction, when steaks were evaluated in the home, flavor affected overall palatability ratings more than tenderness ratings (Huffman et al., 1996). Neely et al. (1998) indicated that flavor may be as important as tenderness in determining overall palatability for fresh beef steaks as both flavor and tenderness correlated similarly with overall like of fresh beef steaks ( $r=0.86$ and 0.85 , respectively). In this study, partial correlations indicated that flavor was more highly correlated with overall acceptability than tenderness $(\mathrm{r}=$ 0.83 and 0.78 , respectively). Clearly, flavor is an important attribute that contributes to consumer satisfaction of beef.

This study offered consumers the unique opportunity to taste steaks before purchasing them, and overall, consumers in Chicago were willing to pay more for the high-marbled samples, which they rated higher in acceptability, whereas consumers in San Francisco were not. Dransfield et al. (1998) reported that consumers were not always willing to pay a premium for steaks that they perceived as more acceptable, which was consistent with the consumers in San Francisco.

When categorized by overall acceptability ratings in both cities, consumers who consistently liked high-marbled steaks and those who consistently liked low-mar- 
bled steaks were willing to pay more for the type of steak they found more acceptable. Overall, $66 \%$ of consumers in this study were not consistent in their overall acceptability ratings or rated samples the same in overall acceptability. Consumers with consistent acceptability ratings represented $33 \%$ of consumers in the study, and of these consumers with consistent acceptability ratings, $71 \%$ of them found high marbling to be more acceptable. Some consumers consistently found lowmarbled steaks to be more acceptable and they were willing to pay more to purchase low-marbled steaks. However, the vast majority of consumers with consistent overall acceptability ratings found high-marbled steaks to be more acceptable and were willing to pay more to purchase high-marbled steaks.

\section{Implications}

When tenderness differences were minimized, consumers who found a particular marbling level more acceptable were willing to pay more for the product they determined to be more acceptable. Although the needs of both groups should be addressed, the vast majority of consumers found high marbling to be most acceptable. Consumers interested in purchasing steaks that will be acceptable in eating quality should perhaps be encouraged to purchase steaks that have higher degrees of marbling than they would normally purchase. Education is needed to help consumers identify steaks that they will find acceptable in eating quality.

\section{Literature Cited}

AMSA. 1978. Guidelines for Cookery and Sensory Evaluation of Meat. Am. Meat Sci. Assoc., Kansas City, MO.

AOAC. 1990. Official Methods of Analysis.15th ed. Assoc. Off. Anal. Chem., Washington, DC.

NCBA. 1996. Beef Industry Long Range Plan. Beef Industry Long Range Plan Task Force, Natl. Cattleman's Beef Assoc., Englewood, CO.

Boleman, S. J., S. L. Boleman, R. K. Miller, J. F. Taylor, H. R. Cross, T. L. Wheeler, M. Koohmaraie, S. D. Shackelford, M. F. Miller, R. L. West, D. D. Johnson, and J. W. Savell. 1997. Consumer evaluation of beef of known categories of tenderness. J. Anim. Sci. 75:1521-1524.

Coppinger, V. M., V. L. Smith, and J. A. Titus. 1980. Incentives and behavior in English, Dutch and sealed-bid auctions. Econ. Inq. 18:1-22.
Coursey, D. L., and V. L. Smith. 1984. Experimental tests of an allocation mechanism for private, public or externality goods. Scand. J. Econ. 86:468-484.

Dransfield, E., F. Zamora, and M. Bayle. 1998. Consumer selection of steaks as influenced by information and price index. Food Qual. Pref. 9:321-326.

Dunsing, M. 1959. Visual and eating preferences of consumer household panel for beef from Brahman-Hereford crossbreds and from Herefords. Food Technol. 13:451-456.

George, M. H., J. D. Tatum, K. E. Belk, and G. C. Smith. 1999. An audit of retail beef loin steak tenderness conducted in eight U.S. cities. J. Anim. Sci. 77:1735-1741.

Huffman, K. L., M. F. Miller, L. C. Hoover, C. K. Wu, H. C. Brittin, and C. B. Ramsey. 1996. Effect of beef tenderness on consumer satisfaction with steaks consumed in the home and restaurant. J. Anim. Sci. 74:91-97.

Killinger, K. M., C. R. Calkins, W. J. Umberger, D. M. Feuz, and K. M. Eskridge. 2004. Consumer visual preference and value for beef steaks differing in marbling level and color. J. Anim. Sci. 82:3288-3293.

Melton, B. E., W. E. Huffman, and J. F. Shogren. 1996. Economic values of pork attributes: Hedonic price analysis of experimental auction data. Rev. Agric. Econ. 18:613-627.

Menkhaus, D. J., G. W. Borden, G. D. Whipple, E. Hoffman, and R. A. Field. 1992. An empirical application of laboratory experimental auctions in marketing research. Agric. Res. Econ. 17:44-55.

Menkhaus, D. J., R. A. Field, and G. D. Whipple. 1990. Economic value of case ready meats as determined by the consumer: Methods. Report to the Beef Industry Council of the National Livestock and Meat Board, Chicago, IL.

Miller, M. F., M. A. Carr, K. L. Crockett, L. C. Hoover, J. L. Montgomery, L. M. Huffman, C. B. Ramsey, and K. W. Wu. 1998. National beef tenderness evaluation by retail consumers. J. Anim. Sci. 76(Suppl. 2):12. (Abstr.).

Neely, T. R., C. L. Lorenzen, R. K. Miller, J. D. Tatum, J. W. Wise, J. F. Taylor, M. J. Buyck, J. O. Reagan, and J. W. Savell. 1998. Beef customer satisfaction: Role of cut, USDA quality grade, and city on in-home consumer ratings. J. Anim. Sci. 76:1027-1033.

NAMP. 1997. Page 31 in The Meat Buyer's Guide. N. Am. Meat Proc. Assoc., Reston, VA.

Savell, J. W., R. E. Branson, H. R. Cross, D. M. Stiffler, J. W. Wise, D. B. Griffin, and G. C. Smith. 1987. National consumer retail beef study: Palatability evaluations of beef loin steaks that differed in marbling. J. Food Sci. 52:517-519, 532.

Savell, J. W., H. R. Cross, J. J. Francis, J. W. Wise, D. S. Hale, D. L. Wilkes, and G. C. Smith. 1989. National consumer retail beef study: Interaction of trim level, price and grade on consumer acceptance of beef steaks and roasts. J. Food Qual. 12:251-274.

Umberger, W. J. 2001. Consumer willingness-to-pay for flavor in beef steaks: An experimental economics approach. Ph.D. Diss., Univ. of Nebraska, Lincoln.

USDA. 1997. United States Standards for Grades of Carcass Beef. Agric. Marketing Serv., USDA, Washington, DC.

Vickery, W. 1961. Counterspeculation, auctions and competitive sealed tenders. J. Finan. 16:8-37. 